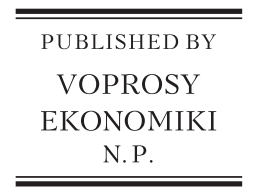

\title{
Examining interrelation between global and national income inequalities ${ }^{\text {th }}$
}

\author{
Marek Dabrowski ${ }^{\text {a,b,c,** }}$ \\ a Bruegel, Brussels, Belgium \\ ${ }^{\mathrm{b}}$ Higher School of Economics, Moscow, Russia \\ ${ }^{\mathrm{c}}$ CASE-Center for Social and Economic Research, Warsaw, Poland
}

\begin{abstract}
The last decade brought increasing attention to income and wealth inequalities in advanced economies because of their increase in several countries and negative social and political implications. However, this debate is often limited to the single-country perspective, disregarding decreasing global income inequalities, i.e. inequalities between individuals in the entire world. This paper focuses mainly on the g lobal dimension of the inequality trends but also tries to update statistics on national inequality trends which, contrary to the dominant narrative, seem to go in various directions depending on a concrete country. Finally, an attempt is made to analyze the potential interrelation and trade-off between decreasing global inequalities and increasing national inequalities and the role of globalization, in its various forms, in such a trade-off.
\end{abstract}

Keywords: income inequality, wealth inequality, income convergence, globalization. JEL classification: D31, D63, F16, F22, F61, F66.

\section{Introduction}

The phenomenon of income and wealth inequalities and their various consequences has always been at the center of economic and social policy debate. Economists, starting from Lewis (1954) and Kuznets (1955), have been interested in the interrelation between income and wealth distribution and econom-

\footnotetext{
th The first version of this paper was presented at the $14^{\text {th }}$ EUROFRAME Conference on Economic Policy Issues in the European Union — Growth and Inequality: Challenges for EU Economies, Berlin, June 9, 2017 (see http:// www.euroframe.org/files/user_upload/euroframe/docs/2017/conference/Session\%207/EUROF17_Dabrowski. pdf). One of the next versions was presented at the XIX International Academic Conference on Economic and Social Development, The Higher School of Economics, Moscow, April 10-13, 2018. The current version was completed on July 22, 2018. The opinions expressed in this paper are the sole responsibility of the author and do not necessarily represent the official position of the institutions with which the author is affiliated.

* E-mail address: marek.dabrowski@bruegel.org
} 
ic growth, i.e. to what extent income and wealth inequalities constitute inevitable side-effects of rapid economic growth, innovation and globalization versus their potentially damaging effect on future economic growth, eradicating poverty, equality of opportunities and social cohesion. ${ }^{1}$

Social policy researchers and practitioners usually include inequality into poverty analysis, assuming that, under a given income-per-capita level, more inequality means more poverty (see Maskin, 2015). This is a standard approach in several publications and statistical databases of international development institutions (see, e.g. UNDP, 2013; 2014; World Bank, 2016) and non-governmental projects (Alvaredo et al, 2017).

Politically, income and wealth inequalities have always been an important topic and hot issue in national debates in many countries of the world, both advanced (AEs) and emerging-market economies (EMEs). In the political economy and political science analyses, they have been seen as the factor which damages democracy (Muller, 1988), leads to political instability (Alesina and Perotti, 1996) and encourages populist policies, especially in developing countries. For example, repeated episodes of populist policies in Latin America in the $20^{\text {th }}$ century were attributed to high income and wealth inequalities in this region (Sachs, 1989; Dornbusch and Edwards, 1991).

The recent few years brought increasing attention to an inequality topic. On the professional ground, this debate was triggered by the broadly publicized but controversial book of Thomas Piketty (2014) and the new series of inequality statistics (e.g. UNDP, 2013; World Bank, 2016; Alvaredo et al., 2017), which pointed to an increasing income inequality within many countries.

The recent wave of populism (of various political colors) in Europe and the US, which led, amongst others, to the victory of the "Leave" vote in the Brexit referendum of 2016, Donald Trump's victory in the 2016 US presidential elections and increasing popularity of populist parties and movements in many other countries, has also been attributed, amongst other factors, to increasing income and wealth inequalities (see Darvas, 2016a; Darvas and Efstathiou, 2016) and disappearance of a middle class, which has been a traditional social base of a political center.

This essay aims to address two specific questions that, in our opinion, have been largely missed in the inequality debate. The first one concerns decreasing global income inequalities, i.e. inequalities between individuals in the entire world (disregarding national borders), even if they still remain on a relatively high level. The second question touches upon the potential interrelation and perhaps trade-off between decreasing global inequalities and increasing national inequalities and the role of globalization in its various forms in such a trade-off. Our analysis is based on a literature review and results of statistical estimations provided by other authors.

The paper is structured as follows. In Section 2, we provide a brief overview of the recent debate and point to its one-sided character. In Section 3, we discuss changes in global income inequality trends and present their various estimates. Section 4 provides recent estimates of within-country (national) income inequalities, with special focus given to AEs. In Section 5, we discuss a potential trade-

\footnotetext{
1 See Ferreira, 1999 for a broader overview of theories of growth and distribution and Furman, 2017 for discussion on whether inequalities are harmful or helpful for economic growth.
} 
off between decreasing global inequalities and increasing national inequalities and the role of economic globalization in its various forms in such a trade-off. In Section 6, we summarize our analysis and present major conclusions.

When we analyze the above-mentioned potential trade-off, we concentrate on AEs despite the fact that inequalities in several EMEs are also on the rise. There are four reasons for such a choice. First, the current inequality debate, including its political dimension, is very much concentrated on AEs (see Section 2). Second, changes in inequality levels in EMEs go in various directions (World Bank, 2016); therefore, it is harder to detect a single trend than in the case of AEs. Third, while globalization may play a role in determining inequality levels in EMEs (Maskin, 2015), there are many other factors in play, often country specific. Fourth, quality of population's income data in EMEs is, on average, lower than in AEs and available cross-country comparable data series are shorter.

The subject of our analysis (global vs. national inequalities) also determines the data choice. Even if the Gini coefficient of income inequality is not a perfect measure (because it remains sensitive to tail distribution - see Slay et al., 2014 for discussion of alternative measures), this is the only available way to make a broader cross-country comparison over longer periods of time.

\section{The recent inequality debate and its shortcomings}

As mentioned in Section 1, the recent round of inequality debates has been triggered by Piketty (2014). His study focused on increase in income and wealth inequalities in AEs, especially in the US and other Anglo-Saxon countries. He attributed this phenomenon to rather rigid class structures of those societies and privileged position of capital as compared to labor.

Although both Piketty's "patrimonial capitalism" diagnosis and, even more, his recipes (a progressive global tax on capital) met criticism (see e.g. Rognlie, 2014; Milanovic, 2014), other researchers and reports (UNDP, 2013; Pichelmann, 2015; World Bank, 2016) confirmed an increasing income inequality within several AEs and EMEs.

These findings, in fact, challenge the so-called Kuznets (1955) reverse U-shaped curve (Fig. 1). Kuznets considered the increase in income inequalities as the only temporary phenomenon associated with the early stage of economic development (as a result of gradual inclusion of individual sectors and industries into modern economic growth). Consistently, with his empirical analysis and contrary to Kuznets, Piketty (2014) presents a normal U-shape curve of income distribution over time, i.e. increasing inequalities after temporary post-WWII period of their reduction. ${ }^{2}$ In turn, Milanovic (2016) suggests "Kuznets waves", i.e. periodic fluctuation in national inequalities determined by political reaction to the observed inequality level (pressure for more redistribution when inequality is high, higher tolerance for inequality when it is low).

Of course, the increasing in-country inequalities have fueled political and ideological debate, very often with high emotional content. This effect has been

\footnotetext{
2 Differences between Kuznets and Piketty curves may originate from the different time of their computation. In 1955, when Kuznets published his seminal paper, income inequality in the US was in decline. Almost 60 years later, when Piketty published his book, it was on the rise.
} 


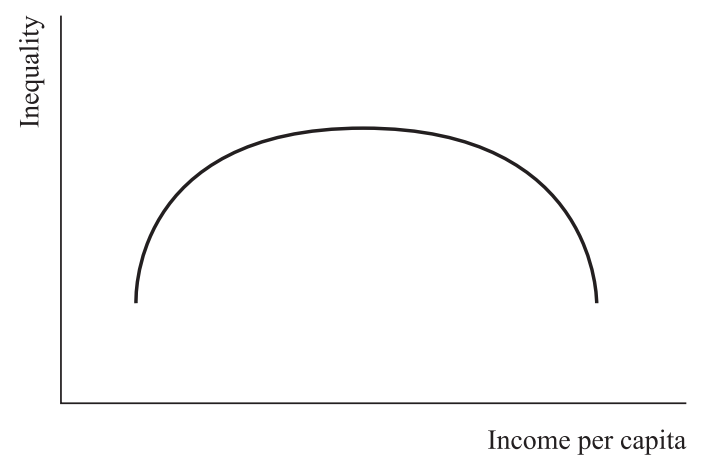

Fig. 1. A stylized Kuznets curve.

Source: Ferreira (1999).

additionally strengthened by the finding that the share of the top $1 \%$ income earners in the total population income increased in several countries (both AEs and EMEs) between 1980 and 2008. In the US and South Africa, it doubled over 30 years, approaching the level of $20 \%$ of total population income (Alvaredo et al., 2013; World Bank, 2016, p. 76, Fig. 4.2; Economist, 2012).

The similar political and emotional effect has been generated by analyses of wealth inequality, which looks even greater than income inequalities ${ }^{3}$ and also tends to increase in the recent period (Credit Suisse, 2016a). It is worth noting, however, that wealth inequality analyses face numerous methodological problems such as short and incomplete data series, their limited cross-country comparability, choice of exchange rate, phenomenon of hidden wealth and others (Credit Suisse, 2016b). Thus, one should be careful when drawing far-reaching conclusions (especially with respect to cross-country comparison and global outlook) based on the existing databases.

The greatest weakness of the current and past inequality debates, however, is related to their narrow character: they have concentrated on inequalities within individual countries. ${ }^{4}$ Furthermore, the global inequality, if it is analyzed at all, is estimated as some sort of average of national inequalities, which is wrong both conceptually and factually (because it misses income-per-capita differences between countries and their changes - see Wolf, 2005). In particular, this may happen when authors try to move from country-level analyses to regional or global ones using either an unweighted or population-weighted average or median of national Gini coefficients (e.g. Li et al., 1998; IMF, 2007; UNDP, 2013; World Bank, 2016, 2018) or other national inequality measures (Alvaredo at al., 2017).

It does not mean that cross-country comparison of national Gini coefficients does not make sense. On the contrary, it may illustrate differences in income distribution in individual countries and help determine factors existing behind those differences. Nevertheless, a very careful interpretation of such cross-country comparisons is always highly recommended. Otherwise, one risks generalizations, which lead to wrong conclusions, like those that the entire world

\footnotetext{
3 Most likely, this is an effect of higher saving rate of higher-income groups of population.

4 Credit Suisse (2016a; 2016b) analysis of global wealth inequalities and Darvas' (2016b) analysis of global and European inequalities are exceptions; they try to present the global picture, disregarding national borders.
} 
economy suffers from more inequality, because national inequalities in most countries are increasing. ${ }^{5}$

One can imagine the hypothetical situation of 200 national economies, each perfectly equal internally (that is, with national Gini coefficients equal to zero) but differing between themselves in terms of income per capita. As result, global income inequality remains high and even increases if high-income countries grow faster than low-income countries. On the contrary, in the situation where low-income countries grow faster than high-income countries, global income inequality may decrease even if national inequalities are growing. This happened exactly in the world economy since the 1980s as documented by Milanovic (2016) and Darvas $(2016 b ; 2018 a)$ and recognized by Piketty (2014) himself.

\section{What do we know about global income inequality?}

The major obstacle to measuring global inequality trends comes from the absence of respective statistics. The household budget surveys (HBS), a key instrument for collecting statistical data on income and wealth inequality, are conducted only nationally. There is no global HBS. As a result, global or regional inequality can be analyzed only indirectly via cross-country differences in income-per capita, using various statistical methods and based on various assumptions on intra-country income distribution ${ }^{6}$.

Limited cross-country comparability of national inequality statistics, their various quality, irregularity of some national HBS, short data series in several countries and incomplete global coverage pose another methodological challenge (World Bank, 2016; Kharas and Seidel, 2018). Some countries use consumption surveys while others - income surveys with the latter generating higher Gini coefficients of income inequality than the former.

Furthermore, cross-country comparability of GDP per capita level in purchasing power parity (PPP) terms is not as obvious as one would imagine. For example, the new PPP international survey of 2011 led to an increase in global GDP in PPP terms by 10 trillion in current international USD, mainly in EMEs, as compared to the previous 2005 PPP conversion rates (Kharas, 2017). Some large EMEs also recalculated (upwards) their nominal GDP. Given the importance of cross-country differences in GDP-per-capita level in determining global income inequality (see below), both factors may influence its eventual estimates.

Within the EU, while there is a harmonized EU-SILK survey, the way in which the Eurostat aggregates national Gini coefficients (weighting them only by the size of population in individual countries but not by income-per-capita levels) raises serious methodological doubts (Darvas, 2016b).

Despite statistical obstacles and methodological uncertainties in estimating global income inequality trends, such attempts have been undertaken since the end of the $20^{\text {th }}$ century. One can mention, amongst others, works of Bourguignon and

\footnotetext{
5 This is exactly the message that one can get from the UNDP (2013) report, starting from its title: "Humanity divided". In particular, see "Overview". The same applies to Alvaredo et al. (2017) and World Bank (2018).

6 Darvas (2016b) provides a comprehensive overview of most frequently used statistical methods and tests their accuracy based on four countries (the US, Australia, Canada and Turkey), which have both national and subnational inequality statistics. He comes to the conclusion that the method of two-parameter distribution is more accurate than others and uses this method to compute global and regional Gini coefficients.
} 


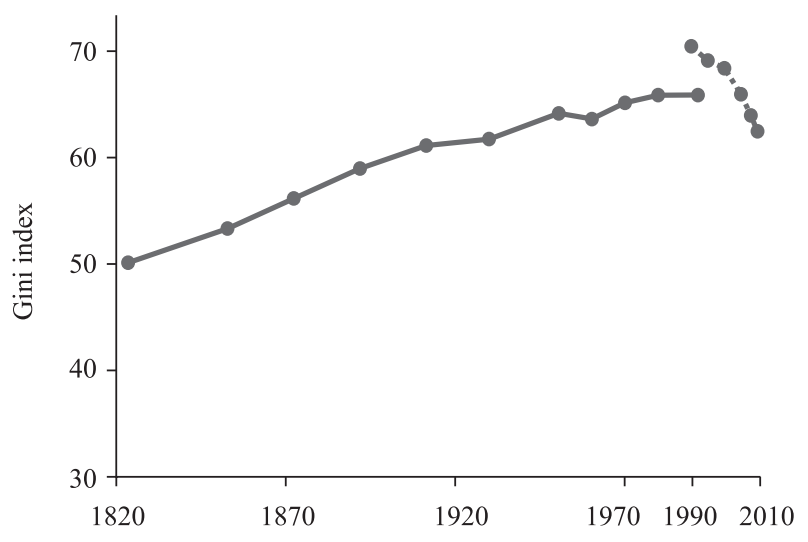

Fig. 2. Global income inequality, 1820-2010.

Source: World Bank (2016, p. 76, Fig. 4.3) based on Bourguignon (2016).

Morrisson (2002), Sala-i-Martin (2006), Anand and Segal (2008), Atkinson and Brandolini (2010) and Milanovic (2012), who developed step-by-step methodology for calculating global income inequality and attempted its statistical estimation for various time periods. Studies of Milanovic (2016), Lakner and Milanovic (2016), World Bank (2016) and Darvas (2016b; 2018a) represent the most recent and most comprehensive assessments of this phenomenon.

Despite methodological differences, all the above-mentioned studies give a similar picture. After a century and a half, following the increase in global inequality by approximately 15 points (as a result of industrial revolution in most of today's AEs), legacy of colonialism, etc. the global Gini coefficient stabilized in 1980s and then started to decline (Fig. 2). Interestingly, the global inequality trend follows, to some degree, the Kuznets curve. The lack of continuity in inequality trend in Fig. 2 results from adoption of various PPP conversion rates for the period until 1990 and after.

Interestingly, in the aftermath of the global financial crisis of 2007-2009, the declining global inequality trend accelerated as result of slower growth of AEs, continuous fast growth of EMEs and partial reversal of the previous growth of national inequalities or their stabilization (Figs. 3-4).

As seen in Figs. 3-4 and confirmed by all the above-mentioned studies, the decrease of global income inequality has been driven predominantly by convergence in GDP-per-capita levels (in PPP terms) between countries, i.e. catching up growth in most of EMEs, especially the most populous ones such as China and India (Fig. 5). ${ }^{7}$ On the other hand, increasing within-country inequalities and demographic changes (faster population growth in the low-income countries) reduce the effect of GDP-per-capita convergence.

The above findings remain broadly in line with the continuous global decline of absolute poverty, including extreme poverty (World Bank 2016, Chapter 2) and growing middle class worldwide, especially in EMEs (Kharas, 2017).

\footnotetext{
7 Not all EMDEs grew fast enough to contribute to GDP per-capita convergence and diminishing global income inequalities. This concerns, for example, a substantial part of Sub-Saharan Africa, which de-converged in relative terms since early 1980s. That is, they diminished the positive contribution of China, India and other fast-growing EMDEs.
} 


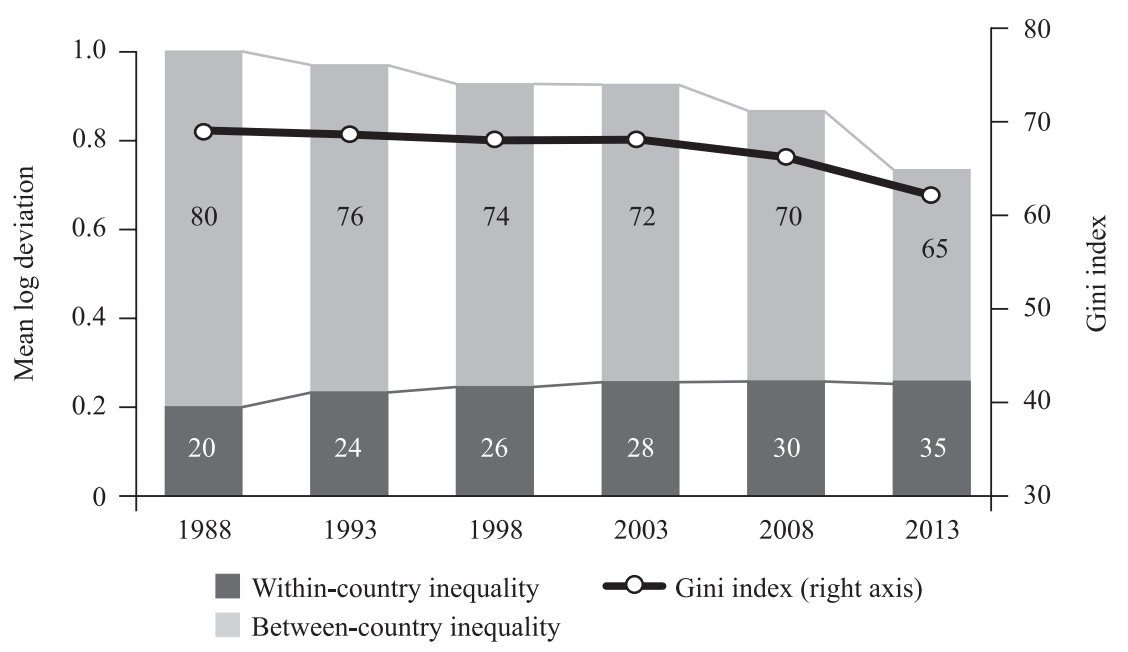

Fig. 3. Global Inequality, 1988-2013.

Source: World Bank (2016, p. 81 , Fig. 4.5) based on Lakner and Milanovic (2016), and Milanovic (2016).

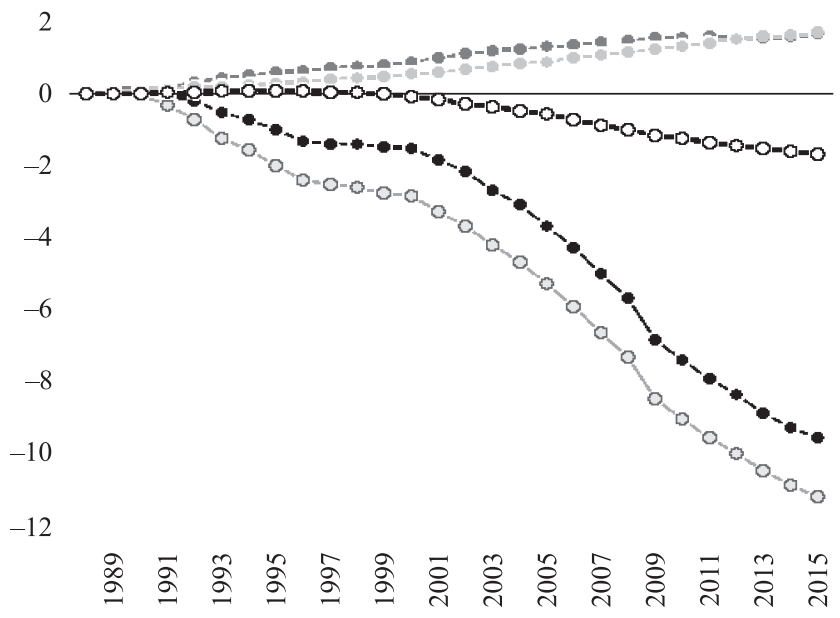

- Cumulative change in global Gini since 1988

due to within-country inequality due to mean income

due to relative population size $\bigcirc$ due to interaction of the three factors

Fig. 4. Changes in the global Gini coefficient of income inequality and their decomposition, 1988-2015.

Note: The estimation is based on the log-normal distribution and uses disposable income (after taxes and transfers). Source: Darvas (2018a, Fig. 2).

Nevertheless, despite its reduction, global income inequality remains at a relatively high level. In 2013, the global Gini coefficient amounted to 62.5 according to the World Bank (2016), 59 according to Darvas (2016b) and 58 according to Darvas (2018a), similarly to the countries with highest inequality such as South Africa, Namibia or Haiti. For 2015, Darvas (2018a) estimates global Gini at the level of 57.

Using the same method as that applied to computing global Gini coefficients, Darvas (2018b) estimated inequality between citizens of the EU28 (Fig. 6). While 


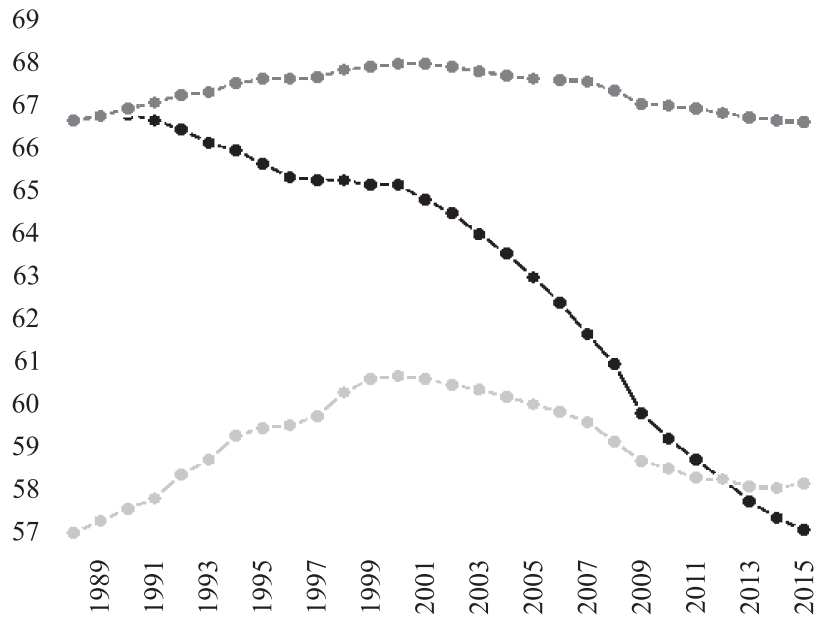

- Baseline (146 countries including China and India)

- 146 countries with "unchanged" China and India

144 countries (excluding China and India)

Fig. 5. Changes in the global Gini coefficient of income inequality: impact of China and India, 1988-2015.

Note: The estimation is based on the log-normal distribution and uses disposable income (after taxes and transfers). Source: Darvas (2018a, Fig. 3) based on the Bruegel dataset-see http://bruegel.org/publications/datasets/ global-and-regional-gini-coefficients/

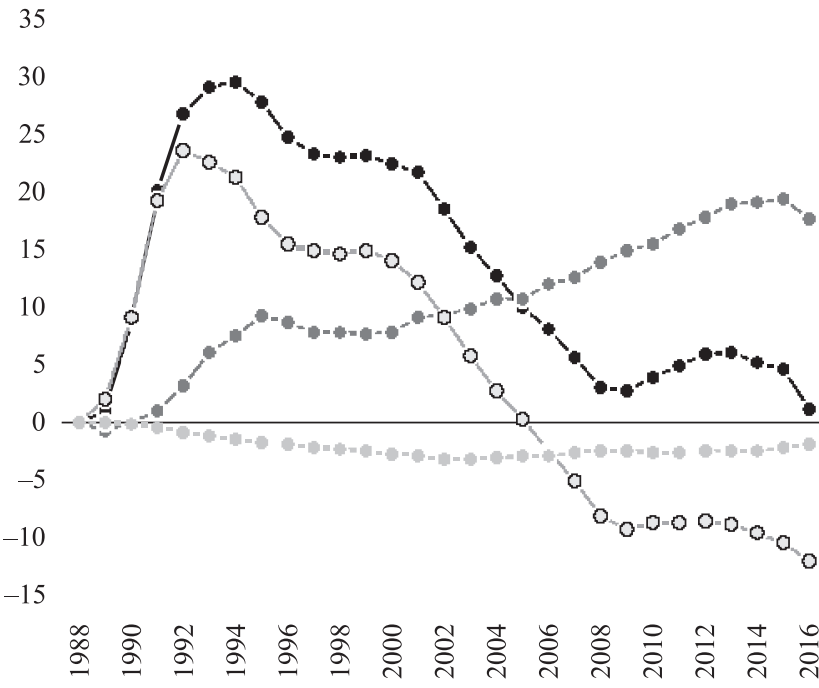

- Cumulative change in EU28 Gini since 1988

due to within-country inequality due to mean income

due to relative population size

Fig. 6. Changes in EU28 Gini coefficient of income inequality and their decomposition, 1989-2013/2015.

Note: The estimation is based on the log-normal distribution and uses disposable income (after taxes and transfers). A small interaction factor is omitted.

Source: Darvas (2018b, Fig. 2) based on Bruegel's dataset-see http://bruegel.org/publications/datasets/ global-and-regional-gini-coefficients/ 
income inequality within the EU28 remains at a much lower level than the global one (Gini coefficient of 33 in 2016), it increased in early 1990s, then gradually decreased between 1994 and 2008, increased slightly between 2009 and 2013 and returned to slow decline after. As in the case of global inequality, GDP-per-capita convergence between individual member states has been a major driving force of this decline while increasing within-countries inequalities has worked in the opposite direction. Overall, the results of Darvas' (2016b) estimation offer a different picture of the EU28 income inequality than the Eurostat data, which are based on a wrong methodology and, therefore, are misleading (see above).

\section{Changes in national income inequality}

Figs. 7-10 present a set of long-term national inequality trends in selected economies based on the Standardized World Income Inequality Database (SWIID), Version 6.2 of March $2018^{8}$ — see Solt (2016). Fig. 7 presents changes in the Gini coefficient of income inequality for four Anglo-Saxon economies (the US, UK, Australia and Canada), Fig. 8 - for four European continental economies (France, Italy, Germany and Sweden), Fig. 9- for BRIC countries (Brazil, Russia, India and China) and Fig. 10 - for the so-called MINT (Mexico, Indonesia, Nigeria and Turkey).

The picture obtained is not so clear and straightforward as one might expect based on Piketty's (2014) analysis and headlines from public debate. Indeed, Piketty was right with respect to the Anglo-Saxon economies (Fig. 7), in particular, the US where the Gini coefficient has been systematically increasing since late 1970s. However, the UK does not fully match the US trend. After the period of increase (from late 1970s until late 1990s), its income inequality started to decrease in 2000s and 2010s.

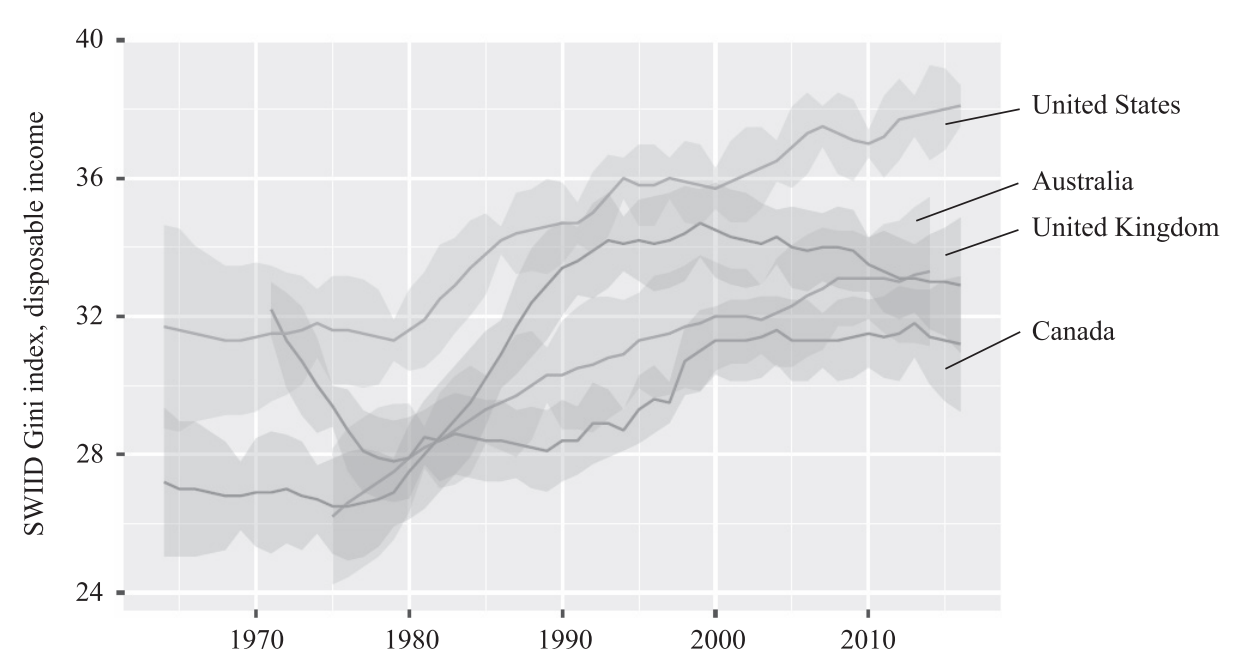

Fig. 7. Gini coefficient of net income inequality: Anglo-Saxon countries, 1960-2013.

Note: Solid lines indicate mean estimates; shaded regions indicate the associated $95 \%$ uncertainty intervals. Source: Standardized World Income Inequality Database (SWIID), Version 6.2 (Solt, 2016).

\footnotetext{
8 For several countries presented in Figs. 7-10 (e.g. China, France, Mexico, Nigeria and Russia), Gini coefficients in the Version 6.2 differ substantially from Version 5.1 published in July 2016
} 
In continental Europe (Fig. 8), one can observe some sort of the convergence trend. While the Gini coefficient in the previously relatively equal societies (Sweden and, to lesser extent, Germany) has been growing systematically since the early 1980s, it has started to decline in Italy and France which represented higher inequality levels in 1960s and 1970s. However in both countries, the declining trend has been somewhat reversed since 2000 (France) and 2008 (Italy).

The situation in large EMEs (Figs. 9-10) is even less homogenous in terms of both inequality levels and trends. Some traditionally high-inequality economies such as Brazil, Mexico and Turkey have shown progress in bringing them down over the last 20-30 years. The same concerns Nigeria where, however, data ends at 2010. On the other hand, previously less-unequal Indonesia has recorded a systematic increase of Gini coefficient since the beginning of the new Millennium. Starting from the second half of 1970s, India has also increased its originally high (over 40) Gini coefficient to more than 48.

The two formerly centrally planned economies (China and Russia) showed an increase in income inequality in the period of its market transition (similar to other countries of the former Soviet Union and Central and Eastern Europe). The Gini coefficient in Russia increased from 35 in late 1980s to 43 in 1996 and then stabilized. China recorded an increase from below 30 in the late 1970s to over 42 in 2008 followed by gradual decrease to 40 in 2015.

The nature of this increase has been often misunderstood (see e.g. Alvaredo et al, 2017). Transition from a centrally planned economy with state ownership of business assets to market economy with dominant private ownership had to lead to higher income and wealth inequalities. Of course, the question remains - was this increase excessive or not? Most probably, it could be lower, if one compares post-transition Gini coefficients of both countries with those of other transition economies.

Despite heterogeneous trends in individual countries, one cannot question the phenomenon of increasing national inequalities in the large part of the world. First, it concerns several of the largest economies: the US, China, Japan (omit-

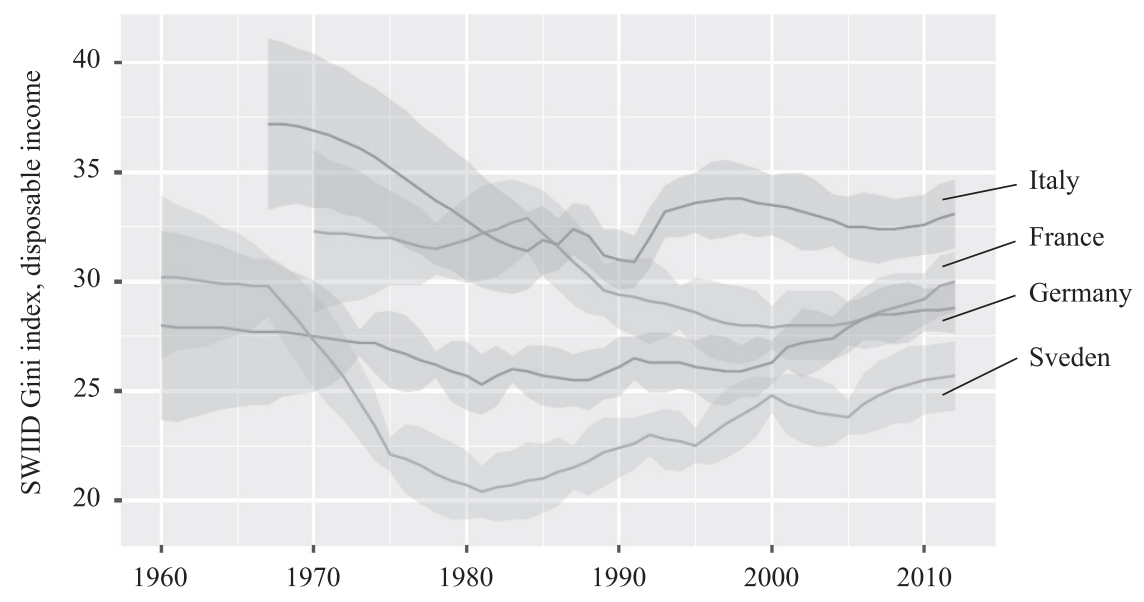

Fig. 8. Gini coefficient of net income inequality: continental Europe, 1960-2013.

Note: Solid lines indicate mean estimates; shaded regions indicate the associated $95 \%$ uncertainty intervals. Source: Standardized World Income Inequality Database (SWIID), Version 6.2 (Solt, 2016). 


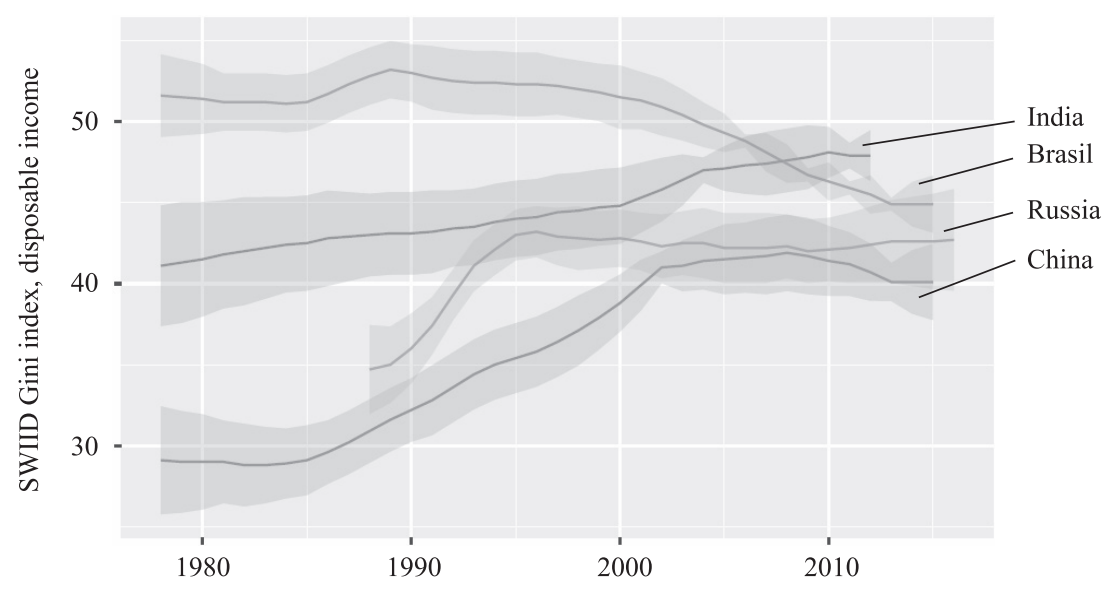

Fig. 9. Gini coefficient of net income inequality: BRIC, 1960-2013.

Note: Solid lines indicate mean estimates; shaded regions indicate the associated $95 \%$ uncertainty intervals. Source: Standardized World Income Inequality Database (SWIID), Version 6.2 (Solt, 2016).

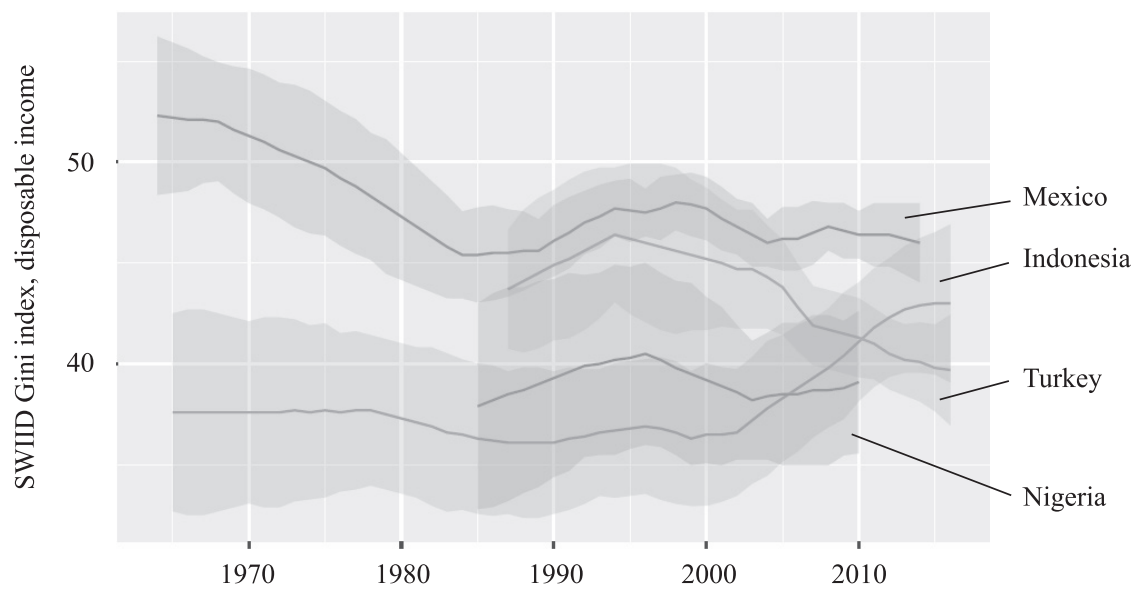

Fig. 10. Gini coefficient of net income inequality: MINT, 1960-2013.

Note: Solid lines indicate mean estimates; shaded regions indicate the associated $95 \%$ uncertainty intervals. Source: Standardized World Income Inequality Database (SWIID), Version 6.2 (Solt, 2016).

ted in Figs. 6-9), Germany, India, Russia and Indonesia. Second, this has been confirmed by results of global inequality estimation discussed in Section 3 (Milanovic, 2016; Bourguignon, 2016; Darvas, 2016b, 2018a): changes in within-country inequalities reduced the effect of GDP-per-capita convergence, contributing to global inequality increase. That is, when changes in populationweighted national inequalities are taken into consideration, one can observe their continued net increase.

Third, the summary analysis of changes in national income inequalities, undertaken by the World Bank (2016, Table 4.1, p. 86), suggests that, between 1993 and 2008, the number of AEs with increasing Gini coefficient (12) was higher than those in which it decreased (5) or remained unchanged (4). These proportions changed in the post crisis period of 2008-2013 with six AEs where Gini further increased, eight where it decreased and six where it remained unchanged. 
One must wait for more recent income inequality data to find whether this change in national inequality dynamics (indirectly confirmed by the faster pace of decline in global inequality - see Chapter 3) signals a new trend or it is just a temporary phenomenon reflecting side effects of the global financial crisis, for example, downturn in financial services (see Chapter 5).

Regarding EMEs, the proportion of countries where Gini increased to those where it decreased is different from AEs (World Bank, 2016, Table 4.1, p. 86). Between 1993 and 2008, Gini increased in 30 EMEs, decreased in 34 and remained unchanged in six countries. Between 2008 and 2013, Gini increased in 13 countries, decreased in 33 countries and remained unchanged in 15 countries. Nevertheless, in the following analysis, we will concentrate on AEs, which are of key importance for discussing our main research question of whether one can face a trade-off between policies aimed at reducing global inequality and its side effect in the form of increasing national inequalities in AEs.

\section{Interrelation between global and national income inequality and the role of globalization}

For the purpose of this analysis, we define economic globalization as "the integration of economic activity across borders, through markets" (Wolf, 2005, p. 14). In practice, it is manifested by a free movement of goods, services, capital, people and information across national borders underpinned by removal of border-related regulatory and policy barriers, national treatment of foreign physical and legal persons and technological progress, which lead to decreasing transaction and transportation costs. Of course, globalization also concerns other aspects of human activity such as security, education and science, culture, healthcare, environmental protection and climate change and others, but they remain outside the remit of our analysis in this paper.

Rapid per-capita growth in most EMEs since early 1990s (faster than in AEs) can be attributed, to large extent, to the globalization process (Maskin, 2015) in all its incarnations. Obviously, globalization is not the only factor helping EMEs in their catching-up growth. One can also mention, for example, domestic economic and institutional reforms, education and health improvement, technological progress, presence of resource rent in the context of the commodity boom in 2000s and early 2010s and, in many instances, the peace dividend associated with terminating domestic and external conflicts. However, those domestic factors have been enhanced by the openness to world markets.

Global trade liberalization allowed moving production of many goods and services from AEs to EMEs with welfare gains for both. Global financial integration improved global capital allocation and helped EMEs to bring large-scale foreign direct investment (FDI) with associated new technologies, managerial and organizational expertise and employees' skill upgrade and helped to develop and modernize their financial sectors, etc. Increasing outward migration generated substantial remittance flows to many EMEs, helped building cross-border business contacts, upgrading skills and learning AEs' culture and experience. Thus, one can conclude that globalization has had a positive impact on decreasing global income inequalities by contributing to income-per capita convergence between lower- and higher-income countries (see Wolf, 2005). However, it is 
fair to note that this view is not unequivocally supported by all authors. Some of them (e.g. Ravallion, 2018) underline the role of domestic reforms and policies; they also claim that technology and knowledge transfer do not necessarily require deep trade and financial integration.

On the other hand, in several AEs, globalization is increasingly seen as the factor responsible for job losses (not only for blue-collar but also white-collar jobs), putting downward pressure on wages and salaries of low- and medium-skilled employees and, therefore, benefiting mainly better-off elites (Milanovic, 2016; Stiglitz, 2016; Sachs, 2017). Politically, globalization may lead to erosion of democratic accountability (Rodrik, 2011). While it helps in expansion of a middle class in EMEs (Milanovic, 2016; Kharas, 2017), it economically undermines part of the traditional middle class in AEs, which constitutes the political base of liberal democracy and a political center (Rodrik, 2011, Stiglitz, 2016). As result, globalization has been recently blamed for generating populist backlash in both Europe and US, the point frequently raised in the 2016 US presidential election campaign ${ }^{9}$.

Discussion of all potential advantages and disadvantages of globalization goes beyond remit of this policy essay. Instead, in our analysis, globalization serves as a phenomenon potentially responsible for both decreasing global inequalities (via GDP-per-capita convergence between countries) and increasing national inequalities in AEs, that is, a phenomenon linking both trends into a causal relationship and policy trade-off.

To answer the question whether there is a trade-off between decreasing global inequality (due to globalization and its positive impact on catching-up growth in EMEs) and increasing within-country inequalities in AEs, we will consider various channels through which globalization may contribute to the latter, partly in response to Stiglitz (2016):

- Free movement of goods and services leads to competition of lower-cost goods and services produced in EMEs against domestic production and, therefore, to cutting the number of jobs in AEs (especially in manufacturing) and putting downward pressure on wages and salaries in case of the remaining jobs in the tradable sector (see Antras et al., 2016). Such effect seems to be in line with the Heckscher-Ohlin-Stolper-Samuelson trade model (Frankel, 2018).

- In addition, free movement of capital allows large corporations to optimize their localization decisions with respect to production and employment within global value chains (GVCs). As a result, many low- and medium-skilled jobs are moved to EMEs (de-location), while high-skilled and high-paid but limited in numbers jobs in management, research and development, product design and marketing, finance and other business related services are expanding in AEs. In many of these activities agglomeration effect, as explained by the new economic geography (NEG) theory (Krugman, 1991), leads to additional territorial concentration of high-paid jobs. ${ }^{10}$ All these effects cause income polarization in AEs. ${ }^{11}$

\footnotetext{
${ }^{9}$ See, e.g., Gros (2016) for critical commentary.

${ }^{10}$ Think about the role of Silicon Valley, Wall Street or City of London.

${ }^{11}$ Michael Kremer and Eric Maskin developed a theoretical model which explains income polarization in EMEs as a result of what they call "internationalization of the production process", i.e. division of labor within GVC (Maskin, 2015). The same model can be used to explain income polarization in AEs.
} 
- Formation of large trans-national companies and integration of financial markets leads to concentration of capital income in few global business and financial centers. This relates, in the first instance, to the financial sector but also to commodity producers and traders and large non-financial corporations (see above).

- Incoming migration from lower-income countries allows employment of lowpaid foreign labor in agriculture, construction, manufacturing, retail, catering and other low-skill services etc., demand for which rapidly increases due to changing lifestyles and population aging in AEs. This may also put downward pressure on wage levels, especially in cases of illegal or informal employment, where it is possible to circumvent the domestic labor market and social policy regulations. However, there is scarce empirical evidence so far confirming the existence of such a downward pressure of immigrants on local wages. It may relate only to unskilled workers (see Dadush, 2018).

- Increasing global cost competition and migration flows make traditional tax and welfare state instruments aimed at reducing national income inequality (progressive personal income taxes, various social benefits and generous public pension schemes) in AEs unsustainable. This hypothesis is questioned by many scholars (see e.g. Ravallion, 2018) who believe there is still sufficient room for domestic policies to correct excessive income inequalities.

- The same effect is caused by the relative ease to move business activity (at least its formal residence) across borders to lower-tax and less-regulated jurisdiction (tax and regulatory arbitrage).

The above list of globalization related effects, potentially responsible for more unequal income distribution in AEs, has the status of a set of hypotheses, which are not easy to be verified empirically.

The IMF (2007) and Jaumotte et al. (2008) are rare examples of quantitative assessment of the impact of globalization on within-country inequalities, for the period of 1981-2003. Conclusions from these studies can be summarized as follows:

- Globalization along with technological progress had a positive impact on increasing national income inequalities, especially in AEs (Fig. 11).

- When disaggregating the globalization phenomenon, trade globalization helped narrowing income inequalities both in AEs and EMEs, while inward and outward FDI increased those inequalities, especially in AEs (Fig. 12); this may indirectly confirm the hypothesis that de-location (associated with outward FDI) reduces the number of low- and medium-skilled jobs and puts downward pressure on labor income in AEs.

A more recent study of Lang and Mendes Tavares (2018, p. 2) on gains from globalization conducted in a panel of 147 countries for the period of 1970-2014 finds that:

- income gains are substantial for countries at early and medium stages of the globalization but the marginal returns diminish as globalization rises;

- there is weak evidence for a Kuznets curve in the full sample of investigated countries but there is statistically significant evidence for such a curve in the group of EMDEs;

- the gains from globalization are concentrated at the top deciles of the national income distributions, especially in AEs; consequently, progress in globalization leads to higher national income inequalities; 

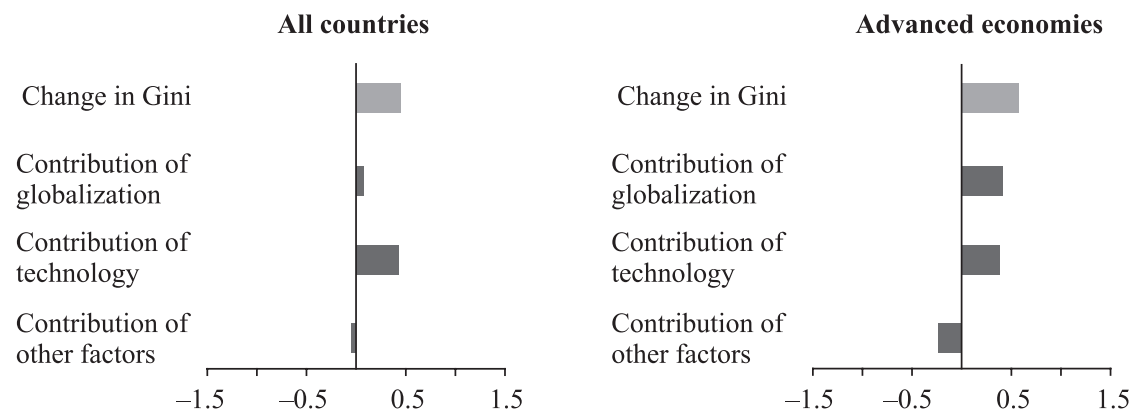

Fig. 11. Decomposition of change in income inequality, 1981-2003 (average annual percentage change).

Source: IMF (2007, p. 49, Fig. 4.9).
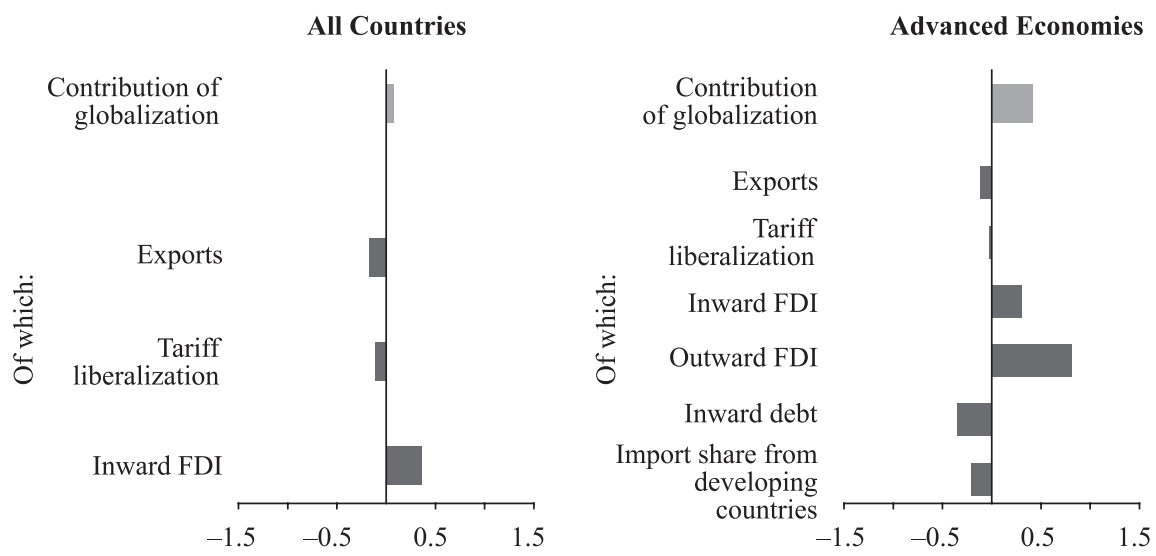

Fig. 12. Decomposition of globalization effect on inequality, 1981-2003 (average annual percentage change).

Source: IMF (2007, p. 50, Fig. 4.10).

- however, there is no evidence of absolute income losses in any income decile and, in EMDEs, all income deciles record gains although disproportionate in favor of top deciles; that is, globalization has a powerful anti-poverty impact;

- increase in FDI is significantly associated with rising national inequality but there is no such evidence for trade flows;

- national policies, in particular, progressive taxation, social transfers and education, can mitigate adverse distributional effects of globalization.

Attempts to go beyond findings of both studies (IMF, 2007; Lang and Mendes Tavares, 2018) require the reliance on fragmental and rather indirect evidence and arguments:

- Perhaps the post-WWII period of lower income inequalities in the US and other AEs can be associated with the relative regress in global economic integration (especially in the financial sphere) which created more policy space for far-going income redistribution within individual AEs. Once global trade and financial integration resumed in 1980s, it became increasingly difficult to sustain many of those instruments against pressure from external competition. Increasing migration flows increased this pressure even further. 
- Change in national inequality trends in the aftermath of the 2007-2009 global financial crisis (stabilization or even decrease of Gini coefficient in several countries) may indirectly support the IMF (2007), Jaumotte et al. (2008) and Lang and Mendes Tavares (2018) findings on the positive impact of financial globalization on income polarization.

- The high share of top corporate managers, financial market specialists and other highly skilled professionals in the top 1\% income earner group in both the US (Economist, 2012) and several European countries (Denk, 2017) seems to confirm the hypothesis on the impact of globalization on job polarization in AEs as a result of new international division of labor (see above). However, such job polarization may also result from technological changes, especially progressing automation and robotization (see Sachs, 2017).

One should admit, however, that neat decomposition of the impact of each individual factor such as globalization, technological progress, changes in education, population aging, macroeconomic policies, labor market policies, market access for various professions and activities, domestic income distribution policies, social welfare etc. on income inequalities is not fully possible due to their partial overlaps (co-integration) and lack of the detailed statistical evidence (Ferreira, 2016).

This leads us to conclude that further empirical research is required to confirm or reject the hypothesis of a positive impact of globalization on income inequalities in AEs (using a more recent dataset) and investigate in detail the channels of such an impact. Particular attention should be given to the potentially corrective role of national policies and to what extent free movement of goods, services, capital and labor puts constraints on them.

\section{Conclusion}

The paper's main purpose was to draw attention to conceptual and methodological shortcomings of the mainstream income inequality debate, which concentrates on increasing national inequalities in some AEs, especially in the US, while disregarding the decrease in global income inequality (between citizens of the world) since the late 1980s. We have also tried to discuss whether there is trade-off between decreasing global inequality and increasing national inequalities in many AEs and what is the role of globalization in its various forms in this tradeoff.

While definitive empirical verification of the trade-off hypothesis is not possible at this stage of research, we cannot exclude its existence based on, amongst others, results of the IMF (2007) and Lang and Mendes Tavares (2018). In particular, the role of financial globalization and the actual room for national income redistribution should be further examined.

In the light of our discussion, globalization process, which helps reducing income-per-capita gap between low- and high-income countries, may also contribute to increasing national income inequalities in part of AEs. Such a potential trade-off offers a new perspective in the inequality debate. While one cannot downplay the negative economic, social and political side-effects of excessive national inequalities, at the same time, it is not possible to ignore positive effects of reducing global inequality (see Bourguignon, 2016). That is, in the increas- 
ingly interconnected and interdependent world, benefits of having more equal national income distribution in AEs will be problematic if they come at the cost of stopping economic convergence of low-income countries. Such a world will be neither just nor safe. In other words, perhaps more unequal income distribution in AEs is the price worth paying for economic and human development progress in the developing world.

In our analysis, we have also found that not all AEs suffer from a continuous increase in in-country income inequality. Furthermore, several countries have managed to stop this trend or even reverse it in recent years. This means that country-specific factors and national policies continue to play an important role, despite the powerful impact of globalization.

\section{Acknowledgements}

Author would like to thank Clemens Kool, Zsolt Darvas, Ben Slay, Rostislav Kapeliushnikov, Leonid Grigoriev and participants of the above-mentioned conferences for their critical comments to the various versions of this paper.

\section{References}

Alesina, A., \& Perotti, R. (1996). Income distribution, political instability and investment. European Economic Review, 40(6), 1203-1228. https://doi.org/10.1016/0014-2921(95)00030-5

Alvaredo, F., Atkinson, A. B., Piketty, T., \& Saez, E. (2013). The top 1 percent in international and historical perspective. The Journal of Economic Perspectives, 27(3), 3-20. https://doi. org/10.1257/jep.27.3.3

Alvaredo, F., Chancel, L., Piketty, T., Saez, E., \& Zucman, G. (2017). World inequality report 2018. World Inequality Lab. http:/wir2018.wid.world/files/download/wir2018-full-reportenglish.pdf

Anand, S., \& Segal, P. (2008). What do we know about global income inequality? Journal of Economic Literature, 46(1), 57-94. https://doi.org/10.1257/jel.46.1.57

Antras, P., de Gortari, P., \& Itskhoki, O. (2016). Globalization, inequality \& welfare. NBER Working Paper, No. 22676. http://www.nber.org/papers/w22676.pdf

Atkinson, A. B., \& Brandolini, A. (2010). On analyzing the world distribution of income. The World Bank Economic Review, 24(1), 1-37. https://doi.org/10.1093/wber/lhp020

Bourguignon, F. (2016). The globalization of inequality. Princeton and Oxford: Princeton University Press.

Bourguignon, F., \& Morrisson, C. (2002). Inequality among world citizens: 1820-1992. The American Economic Review, 92(4), 727-744. Retrieved from http://piketty.pse.ens.fr/files/ BourguignonMorrisson2002.pdf. https://doi.org/10.1257/00028280260344443

Credit Suisse. (2016a). Global wealth report 2016. Credit Suisse Research Institute, November. http://publications.credit-suisse.com/tasks/render/file/index.cfm?fileid=AD783798-ED07E8C2-4405996B5B02A32E

Credit Suisse. (2016b). Global wealth databook 2016. Credit Suisse Research Institute, November. http://publications.credit-suisse.com/tasks/render/file/index.cfm?fileid=AD6F2B43-B17B345E-E20A1A254A3E24A5

Dadush, U. (2018). The economic effects of refugee return. Economics: The OpenAccess, OpenAssessment E-Journal, 12 (2018-33): 1-17. http://dx.doi.org/10.5018/economics-ejournal. ja.2018-33

Darvas, Z. (2016a). Brexit vote boosts case for inclusive growth. Bruegel blog, July 13. http:// bruegel.org/2016/07/brexit-vote-boosts-case-for-inclusive-growth/ 
Darvas, Z. (2016b). Some are more equal than others: new estimates of global and regional inequality. Bruegel Working Paper, No. 8/2016. http://bruegel.org/wp-content/uploads/2016/11/ WP $08 \_16-1 . p d f$

Darvas, Z. (2018a). Global income inequality is declining - largely thanks to China and India. Bruegel blog, April 19. http://bruegel.org/2018/04/global-income-inequality-is-declininglargely-thanks-to-china-and-india/

Darvas, Z. (2018b). European income inequality begins to fall once again. Bruegel blog, April 30. http://bruegel.org/2018/04/european-income-inequality-begins-to-fall-once-again/

Darvas, Z., \& Efstathiou, K. (2016). Income inequality boosted Trump vote. Bruegel blog, November 9. http://bruegel.org/2016/11/income-inequality-boosted-trump-vote/

Denk, O. (2017). Who are the top 1 percent earners in Europe? Paper presented at the $14^{\text {th }}$ EUROFRAME Conference on Economic Policy Issues in the European Union - Growth and Inequality: Challenges for EU Economies, Berlin, June 9. http://www.euroframe.org/files/ user_upload/euroframe/docs/2017/conference/Session\%202/EUROF17_Denk.pdf

Dornbusch, R., \& Edwards, S. (1991). Macroeconomic populism in Latin America. NBER Working Paper, No. 2986. http://www.nber.org/papers/w2986.pdf

Economist (2012). Income inequality: Who exactly are the 1\%? The Economist, January 21. http:// www.economist.com/node $/ 21543178$

Ferreira, F. H. G. (1999). Inequality and economic performance. A brief overview to theories of growth and distribution. Text for World Bank's Web Site on Inequality, Poverty, and Socio-economic Performance. June. http://siteresources.worldbank.org/INTPGI/Resources/ Inequality/ferreira.pdf

Ferreira, F. (2016). Kuznets waves and the great epistemological challenge to inequality analysis. The World Bank blogs, April 27. http://blogs.worldbank.org/impactevaluations/kuznetswaves-and-great-epistemological-challenge-inequality-analysis

Frankel, J. (2018). Does trade fuel inequality? Project Syndicate, January 2. https://www. project-syndicate.org/commentary/globalization-trade-inequality-relationship-by-jeffreyfrankel-2018-01

Furman, J. (2017). Should policymakers care whether inequality is helpful or harmful for growth? Paper for the Rethinking Macroeconomic Conference, Peterson Institute for International Economics, Washington, DC, October 11-12. https://piie.com/system/files/documents/ furman20171012paper.pdf

Gros, D. (2016). Is globalization really fueling populism? Project Syndicate, May 6. https://www. project-syndicate.org/commentary/understand-factors-behind-rising-populism-by-danielgros-2016-05

IMF. (2007). Globalization and inequality. In: World economic outlook: Globalization and inequality (Ch. 4,pp. 31-65). Washington, DC: International Monetary Fund, October. https://www.imf.org/ external/pubs/ft/weo/2007/02/pdf/c4.pdf

Jaumotte, F., Lall, S., \& Papageorgiou, C. (2008). Rising income inequality: Technology, or trade and financial globalization? IMF Working Papers, No. WP/08/185. http://www.imf.org/ / media/websites/imf/imported-full-text-pdf/external/pubs/ft/wp/2008/ wp08185.ashx

Kharas, H. (2017). The unprecedented expansion of the global middle class: An update. The Brookings Global Working Paper Series, No. 100. https://www.brookings.edu/wp-content/ uploads/2017/02/global_20170228_global-middle-class.pdf

Kharas, H., \& Seidel, B. (2018). What's happening to the world income distribution? The elephant chart revisited. The Brookings Global Working Paper Series, No. 114. https://www.brookings. edu/wp-content/uploads/2018/04/workingpaper114-elephantchartrevisited.pdf

Krugman, P. (1991). Geography and trade. Cambridge, MA: MIT Press.

Kuznets, S. (1955). Economic growth and income inequality. The American Economic Review, $45(1), 1-28$.

Lakner, C., \& Milanovic, B. (2016). Global income distribution: From the fall of the Berlin Wall to the Great Recession. The World Bank Economic Review, 30(2), 203-232. https://doi. org/10.1093/wber/lhv039

Lang, V. L., \& Mendes Tavares, M. (2018). The distribution of gains from globalization. IMF Working Paper, No. WP/18/54. http://www.imf.org/ /media/Files/Publications/WP/2018/ wp1854.ashx 
Lewis, W. A. (1954). Economic development with unlimited supplies of labour. Manchester School, 22(2), 139-191. https://doi.org/10.1111/j.1467-9957.1954.tb00021.x

Li, H., Squire, L., \& Zou, H.-F. (1998). Explaining international and intertemporal variations in income inequality. Economic Journal (London), 108(446), 26-43. Retrieved from http://www. jstor.org/stable/2565735. https://doi.org/10.1111/1468-0297.00271

Maskin, E. (2015). Why haven't global markets reduced inequality in emerging economies? World Bank Economic Review, 29 (Supply 1), S48-S52. https://doi.org/10.1093/wber/lhv013

Milanovic, B. (2012). Global income inequality by the numbers: In history and now (Policy Research Working Paper No. WPS6259). Washington, DC: World Bank. http://documents. worldbank.org/curated/en/959251468176687085/pdf/wps6259.pdf

Milanovic, B. (2014). The return of "patrimonial capitalism": A review of Thomas Piketty's Capital in the twenty-first century. Journal of Economic Literature, 52(2), 519-534. https:// doi.org/10.1257/jel.52.2.519

Milanovic, B. (2016). Global inequality: A new approach for the age of globalization. Cambridge, MA: Harvard University Press.

Muller, E. N. (1988). Democracy, economic development, and income inequality. American Sociological Review, 53(1), 50-68. https://doi.org/10.2307/2095732

Pichelmann, K. (2015). When "secular stagnation" meets Piketty's capitalism in the $21^{\text {st }}$ century. Growth and inequality trends in Europe reconsidered. European Economy-. Economic Papers, (551). 10.2765/005310

Piketty, T. (2014). Capital in the twenty-first century. Cambridge, MA: Harvard University Press.

Ravallion, M. (2018). Inequality and globalization: A review essay. Journal of Economic Literature, 56(2), 620-642. https://doi.org/10.1257/jel.20171419

Rodrik, D. (2011). The globalization paradox. Democracy and the future of the world economy. New York and London: W.W. Norton.

Rognlie, M. (2014). A note on Piketty and diminishing returns to capital. Unpublished manuscript. http://mattrognlie.com/piketty_diminishing_returns.pdf

Sala-i-Martin, X. (2006). The world distribution of income: The falling poverty and ... convergence, period. The Quarterly Journal of Economics, 121(2), 351-397. https://doi.org/10.1162/ qjec.2006.121.2.351

Sachs, J. D. (1989). Social conflict and populist policies in Latin America. NBER Working Paper, No. 2897. http://www.nber.org/papers/w2897.pdf

Sachs, J. D. (2017). America, we still have a jobs problem. CNN.com, July 7. http://edition.cnn. com/2017/07/07/opinions/americas-jobs-problem-sachs/index.html

Slay, B., Danilova-Cross, E., Papa, J., Peleah, M., Marnie, S., \& Henrich, C. (2014). Poverty, inequality, and vulnerability in the transition and developing economies of Europe and Central Asia. UNDP Regional Bureau for Europe and CIS, UNDP Bureau for Policy and Programme Support. http://www.eurasia.undp.org/content/dam/rbec/docs/Poverty\%20Inequality $\% 20$ and $\% 20$ Vulnerability.pdf?download

Solt, F. (2016). The standardized world income inequality database. Social Science Quarterly, 97(5), 1267-1281. https://doi.org/10.1111/ssqu.12295

Stiglitz, J. (2016). Globalization and its new discontents. Project Syndicate, August 5. https:// www.project-syndicate.org/commentary/globalization-new-discontents-by-joseph-e-stiglitz-2016-08

UNDP. (2013). Humanity divided: Confronting inequality in developing countries. New York: United Nations Development Programme, Bureau for Development Policy. http://www. undp.org/content/dam/undp/library/Poverty\%20Reduction/Inclusive\%20development/ Humanity\%20Divided/HumanityDivided_Full-Report.pdf?download

Wolf, M. (2005). Why globalization works ( $2^{\text {nd }}$ ed.). New Haven, CT and London: Yale University Press.

World Bank. (2016). Poverty and shared prosperity 2016: Taking on inequality. Washington, DC: World Bank. https://doi.org/10.1596/978-1-4648-0958-3

World Bank. (2018). Growing united: Upgrading Europe's convergence machine. World Bank report on the European Union. Washington, DC: World Bank. http://pubdocs.worldbank.org/ en/949971523912259619/Growing-United-v02-online-18-03-06-Main-Report.pdf 